\title{
Water content of roasted coffee impact on grinding behaviour, extraction, and aroma retention
}

\section{Journal Article}

Author(s):

Baggenstoss, Juerg; Perren, Rainer; Escher, Felix

Publication date:

2008

Permanent link:

https://doi.org/10.3929/ethz-b-000015069

Rights / license:

In Copyright - Non-Commercial Use Permitted

Originally published in:

European Food Research and Technology 227(5), https://doi.org/10.1007/s00217-008-0852-8 


\title{
Water content of roasted coffee: impact on grinding behaviour, extraction, and aroma retention
}

\author{
Juerg Baggenstoss $\cdot$ Rainer Perren $\cdot$ Felix Escher
}

Received: 01 November 2007 / Revised: 18 February 2008 / Accepted: 29 February 2008 / Published online: 18 March 2008 (C) Springer-Verlag 2008

\begin{abstract}
Normal and long time roasting trials were carried out on industrial scale. Different amounts of water were applied during quenching, resulting in water contents in the range of 2.3-8.8 g/100 g wb. Coffees were ground immediately after cooling, and after equilibration times of 6 and 24 h. Particle size distribution of ground coffees, percolation time, and extraction properties were investigated on an espresso coffee machine. Coffees ground after $24 \mathrm{~h}$ resting time were subjected to storage trials to determine aroma stability as influenced by water content. Coffees with high moisture content exhibited coarser particles upon grinding, and equilibration time prior to grinding was needed for coffees with high water content to improve grinding results. Coffees with low water content did not exhibit this time dependency prior to grinding. Coffees with low water content were extracted more effectively than high moisture coffees, and percolation was slower. During open and closed storage, evolution of hexanal and sulfides was highly sensitive to water content. However, differences in evolution of other aroma compounds were found during closed storage only, where moisture content had a negative impact on aroma stability of the coffees subjected to investigation.
\end{abstract}

Keywords Coffee roasting - Grinding - Water content . Aroma retention $\cdot$ Extraction properties $\cdot$ SPME-GC-MS

\footnotetext{
J. Baggenstoss $\cdot$ R. Perren $\cdot$ F. Escher $(\bowtie)$

Institute of Food Science and Nutrition,

Swiss Federal Institute of Technology (ETH),

8092 Zurich, Switzerland

e-mail: escher@ilw.agrl.ethz.ch

J. Baggenstoss

e-mail: juerg.baggenstoss@ilw.agrl.ethz.ch
}

\section{Introduction}

Coffee beverages are prepared by extracting and dispersing the desired types and amount of components from roasted coffee beans into water. Thereby, size reduction of the roasted beans by grinding is a prerequisite for controlled extraction and dispersion. The formation of small particles and large particle surface are essential for rapid liberation of carbon dioxide, reduction of diffusion distance for soluble substances during extraction, and improved transfer of colloidal substances to the liquid phase [1]. Coffee is usually comminuted by gap grinding using roller, conical, or flat cutters. In industrial practice, roller cutters are the most frequently used grinders. Due to specific structural properties of roasted coffee beans, a crushing phase for reducing the coffee bean into coarse pieces is necessary prior to fine grinding. In grinding devices, this is achieved by using cutters with unequal teeth (flat and conical cutters) or by using series of grinding stages with decreasing gap width in roller grinding systems [2].

Not much information is available on coffee grinding dynamics. Using computer simulation of the action of a disk grinder on a particle composed of several cells, it was shown that the exerted stress was not uniform and resulted in formation of one large and several very small particles [3]. As expected, grinding behaviour of coffee beans depends on water content after roasting. According to grinding tests of beans with different water contents, the proportion of fine particles and the particle-specific surface increased when the water content was low $[4,5]$.

The efficiency of extraction is controlled by the particle size distribution of ground coffee. Basically, extraction rate and extent depend on the percolation properties of the bed of ground coffee, the wettability of the individual particles in the aqueous system, and the overall particle surface for 
diffusion. Computer simulation showed that coarsely ground coffee lead to the build-up of large channels in which the extraction water flows at high velocities so that extraction yields are low [6]. On the other hand, if the particle size becomes too small, filters are clogged, particles may even flow through the filters, and over-extraction occurs due to extended contact time. Also, a balance between wettability, for which particles must not be too small, and diffusion, which increases with decreasing particle size, must be attained. Therefore, in order to optimise extraction one tries to obtain a bimodal particle size distribution with medium particle size of about $0.5 \mathrm{~mm}$ and a small amount of fine particles [2,7]. For espresso type beverages, for which careful adjustment of grinding parameters is particularly important with regard to final cup quality, the bimodal particle size distribution ensures a proper percolation due to the coarse fraction and at the same time, high diffusion rates from small particles [2].

The influence of grinding on extraction was also studied for specific compounds. It was shown that extraction of caffeine was more efficient from finely ground than from coarsely ground coffee $[8,9]$. Overall flavour profile of espresso coffee made from a blend with $80 \%$ Arabica and $20 \%$ Robusta coffee was judged as a function of grinding fineness. It was found that finely ground coffee exhibited better aroma and flavour characteristics than coarsely ground coffee [4].

Final water content of coffee beans after roasting does not only influence the grinding behaviour as stated above. There is also evidence that water content controls aroma retention and stability during storage of roasted coffee [10], which means that there exists a dual dependence of cup quality on water content, one direct and one indirect via grinding behaviour. The present investigation aims at elucidating the influence of water content on grinding, percolation, and extraction properties of ground coffee, as well as aroma stability during storage of ground coffee in an open and a closed packed system.

\section{Materials and methods}

Roasting process and process characterisation

\section{Roasting}

Green arabica coffee from Colombia (Excelso) was roasted at industrial scale using a RT1000 tangential roaster (Probat Ltd, Emmerich, Germany). A normal and a long time process were used. Normal time roasting was carried out with a batch size of $120 \mathrm{~kg}$ and roasting time of approximately $340 \mathrm{~s}$. Inlet air temperature was $350{ }^{\circ} \mathrm{C}$ in the first stage of roasting, and was reduced to $330{ }^{\circ} \mathrm{C}$ when bulk temperature reached $160{ }^{\circ} \mathrm{C}$. Long time roasting was carried out with a batch size of $170 \mathrm{~kg}$ and roasting time was around $650 \mathrm{~s}$. Roasting temperature in the long time process was lower. Initial inlet air temperature was $310{ }^{\circ} \mathrm{C}$, and was reduced to $300{ }^{\circ} \mathrm{C}$ when bulk temperature attained $175^{\circ} \mathrm{C}$. All batches were roasted to the same degree of roast, but different amounts of water were applied during the cooling step resulting in different water contents. Roasting parameters are illustrated in Table 1.

\section{Colour}

Coffee was ground, gently pressed, and the colour was measured using a CR 310 photometer (Konica Minolta Imaging, Dietikon, Switzerland). Results were expressed in the CIE $L^{*} a^{*} b^{*}$ colour space. $L^{*}$-values were used as a measure of roast degree, where $L^{*}=0$ means black, and $L^{*}=100$ means white.

\section{Water content}

Water content of roasted coffee was determined gravimetrically after drying $5 \mathrm{~g}$ of ground coffee at $103{ }^{\circ} \mathrm{C}$ for $5 \mathrm{~h}$.
Table 1 Roasting parameters and roasted coffee properties

$N T$ normal time roast, $L T$ long time roasts

\begin{tabular}{llllllll}
\hline Batch & $\begin{array}{l}\text { Batch } \\
\text { size }(\mathrm{kg})\end{array}$ & $\begin{array}{l}\text { Roasting } \\
\text { time }(\mathrm{s})\end{array}$ & $\begin{array}{l}\text { Final bulk } \\
\text { temperature } \\
\left({ }^{\circ} \mathrm{C}\right)\end{array}$ & $\begin{array}{l}\text { Colour } \\
\left(L^{*}\right)\end{array}$ & $\begin{array}{l}\text { Water } \\
\text { used for } \\
\text { quenching }(L)\end{array}$ & $\begin{array}{l}\text { Water } \\
\text { content } \\
(\mathrm{g} / 100 \mathrm{~g} \mathrm{wb})\end{array}$ & $\begin{array}{l}\text { Bulk } \\
\text { density } \\
(\mathrm{g} / \mathrm{L})\end{array}$ \\
\hline Normal time roasts & & & & & & \\
NT 1 & 100 & 343.7 & 225.0 & 22.6 & 12 & 2.3 & 335 \\
NT 2 & 100 & 340.0 & 222.2 & 23.3 & 20 & 5.1 & 347 \\
NT 3 & 100 & 340.5 & 222.2 & 22.6 & 30 & 8.8 & 344 \\
Long time roasts & & & & & & 353 \\
LT 1 170 & 651.5 & 222.1 & 23.5 & 16 & 2.9 & 358 \\
LT 2 & 170 & 637.7 & 222.1 & 23.4 & 25 & 3.6 & 358 \\
LT 3 & 170 & 641.4 & 222.1 & 23.1 & 32 & 5.9 & \\
\hline
\end{tabular}


Grinding and packaging

\section{Grinding}

Roasted coffees were ground with a UW246 roll grinder (Probat Ltd, Emmerich, Germany). The grinder consisted of three serial anvil rollers in which the first one served as a pre-crusher and the following two served as fine grinders. The gap between the rollers was set to 1.4 and 0.22 (arbitrary units) for the first and the second fine grinding unit, respectively. To determine the impact of resting time upon grinding, roasted coffees were ground immediately, 6 and $24 \mathrm{~h}$ after roasting.

\section{Particle size distribution of ground coffee}

Analysis of particle size distribution was carried out using the image analysis sensor QICPIC (Sympatec Ltd, Clausthal-Zellerfeld, Germany). The sensor worked with a pulsed light source and sub-nanosecond illumination. Results were obtained as sum of distribution and distribution density.

\section{Packaging}

For experiments concerning extraction yield, percolation time, and evolution of aroma compounds, portions of $6.3 \mathrm{~g}$ ground coffee were packaged into small synthetic containers and sealed under normal atmosphere.

\section{Extraction yield and percolation time}

Extraction yield and percolation time of ground coffees were determined using a commercial espresso machine (Gaggia S.p.a, Robecco Sul Naviglio, Italy). Coffee was extracted for $20 \mathrm{~s}$, then the extract was dried for $70 \mathrm{~h}$ at $103{ }^{\circ} \mathrm{C}$, and extraction yield was determined gravimetrically. To determine percolation time, the time necessary for percolation of $60 \mathrm{~mL}$ water was measured.

Evolution of aroma compounds during storage of roast and ground coffee

Three aldehydes (2-methylbutanal, 3-methylbutanal, hexanal), two diketones (2,3-butanedione, 2,3-pentanedione), two sulfides (dimethyl sulfide, dimethyl trisulfide), one heterocyclic (pyridine), and one phenolic compound (4-vinylguaiacol) were analysed by headspace solid-phase microextraction-gas chromatography-mass spectrometry (SPME-GC-MS) and quantified by means of stable isotope dilution assay using the method described in [10]. Ground coffee was weighed in a $100 \mathrm{~mL}$ flask and extracted with boiling water ( $5 \%$ Tc for dimethyl sulfide and hexanal, $1 \% \mathrm{Tc}$ for the other compounds) under constant stirring for $10 \mathrm{~min}$ while the flask was kept closed. The flask was subsequently cooled under cold water, and the stable isotope labelled standards $\left[{ }^{2} \mathrm{H}_{6}\right]$-dimethyl sulfide and $\left[{ }^{2} \mathrm{H}_{2}\right]$-hexanal (flasks with $5 \% \mathrm{Tc}$ ), or $\left[{ }^{2} \mathrm{H}_{2}\right]-3$ methylbutanal, $\left[{ }^{13} \mathrm{C}_{4}\right]$-2,3-butanedione, $\left[{ }^{13} \mathrm{C}_{2}\right]-2,3$-pentanedione, $\left[{ }^{2} \mathrm{H}_{6}\right]$-dimethyl trisulfide, $\left[{ }^{2} \mathrm{H}_{5}\right]$-pyridine, and $\left[{ }^{2} \mathrm{H}_{3}\right]$-4-vinylguaiacol (flasks with $1 \% \mathrm{Tc}$ ) were added in defined amounts. Coffee suspensions were stirred for another $10 \mathrm{~min}$, and aliquots of $7 \mathrm{~mL}$ were transferred to headspace vials. Headspace SPME sampling was carried out using a Supelco 50/30 $\mu \mathrm{m}$ StableFlex divinylbenzene/ carboxen/polydimethylsiloxane fiber (Supelco, Buchs, Switzerland). Sampling time was $10 \mathrm{~min}$ at $40^{\circ} \mathrm{C}$. The fiber was desorbed in the splitless injector of a Fisons 8000Series gas chromatograph (Thermo Electron, Allschwil, Switzerland) with splitless time of $240 \mathrm{~s}$. Separation was carried out using a $60 \mathrm{~m} \times 0.25 \mathrm{~mm} \times 0.25 \mu \mathrm{m} Z \mathrm{ZB}-1701$ column (Phenomenex, Aschaffenburg, Germany). For hexanal and dimethyl sulfide, the temperature program was $40{ }^{\circ} \mathrm{C}(6 \mathrm{~min}), 4{ }^{\circ} \mathrm{C} / \mathrm{min}, 135^{\circ} \mathrm{C}(0 \mathrm{~min}), 40^{\circ} \mathrm{C} / \mathrm{min}$, $240{ }^{\circ} \mathrm{C}(5 \mathrm{~min})$. Temperature program for the other compounds was $40^{\circ} \mathrm{C}(4 \mathrm{~min}), 4{ }^{\circ} \mathrm{C} / \mathrm{min}, 140{ }^{\circ} \mathrm{C}(0 \mathrm{~min})$, $40{ }^{\circ} \mathrm{C} / \mathrm{min}, 240^{\circ} \mathrm{C}(5 \mathrm{~min})$. As a carrier gas, helium 5.6 was used at column head pressure of $135 \mathrm{kPa}$. The gas chromatograph was coupled to a quadrupole mass spectrometer (SSQ710, Finnigan MAT, San Jose, CA, USA), operated in the EI mode with an ionisation potential of $70 \mathrm{eV}$. Detection was carried out in the single ion monitoring (SIM) mode. The following mass traces $(\mathrm{m} / \mathrm{z}$ ) were followed: 43 (2,3-butanedione), $45\left(\left[{ }^{13} \mathrm{C}_{4}\right]-2,3\right.$-butanedione), 47 (dimethyl sulfide), $50\left(\left[{ }^{2} \mathrm{H}_{6}\right]\right.$-dimethyl sulfide), 56 (hexanal), 58 ( $\left[{ }^{2} \mathrm{H}_{2}\right]$-hexanal), 71 (3-methylbutanal), 73 ( $\left[{ }^{2} \mathrm{H}_{2}\right]$-3-methylbutanal), 79 (pyridine), 84 ( $\left[{ }^{2} \mathrm{H}_{5}\right]$-pyridine), 86 (2-methylbutanal), $88 \quad\left(\left[{ }^{2} \mathrm{H}_{2}\right]-3\right.$-methylbutanal for quantification of 2-methylbutanal), 100 (2,3-pentanedione), 102 ( $\left[{ }^{13} \mathrm{C}_{2}\right]-2,3$-pentanedione), 126 (dimethyl trisulfide), $132\left(\left[{ }^{2} \mathrm{H}_{6}\right]\right.$-dimethyl trisulfide), 150 (4-vinylguaiacol), and $153\left(\left[{ }^{2} \mathrm{H}_{3}\right]-4\right.$-vinylguaiacol).

Storage trials were carried out with all long time roasted and one normal time roasted coffee, ground after $24 \mathrm{~h}$ resting time (NT 3, LT 1, LT 2, LT3). Ground coffee was stored under open conditions $\left(25^{\circ} \mathrm{C}\right.$, normal atmosphere), and in portions of $6.3 \mathrm{~g}$ in tightly sealed small containers with normal atmosphere at $25^{\circ} \mathrm{C}$. Samples of open stored coffee were taken after $1,3,8,15,22,37$, and 56 days, whereas one sample of each coffee was packaged under nitrogen, directly after grinding, and analysed as a reference with a period of $24 \mathrm{~h}$ between packing and analysis. In the case of packaged coffee, aroma was analysed after 8, 23, 41,56 , and 224 days. 


\section{Results}

Particle size distribution of ground coffee

A typical particle distribution of a ground roasted coffee is shown in Fig. 1. The distribution in particle size is bimodal with a relative maximum at average particle size of around $70 \mu \mathrm{m}$ and an absolute maximum at average particle size of around $425 \mu \mathrm{m}$. To characterise particle distribution of ground coffees, three parameters were found to be sufficient

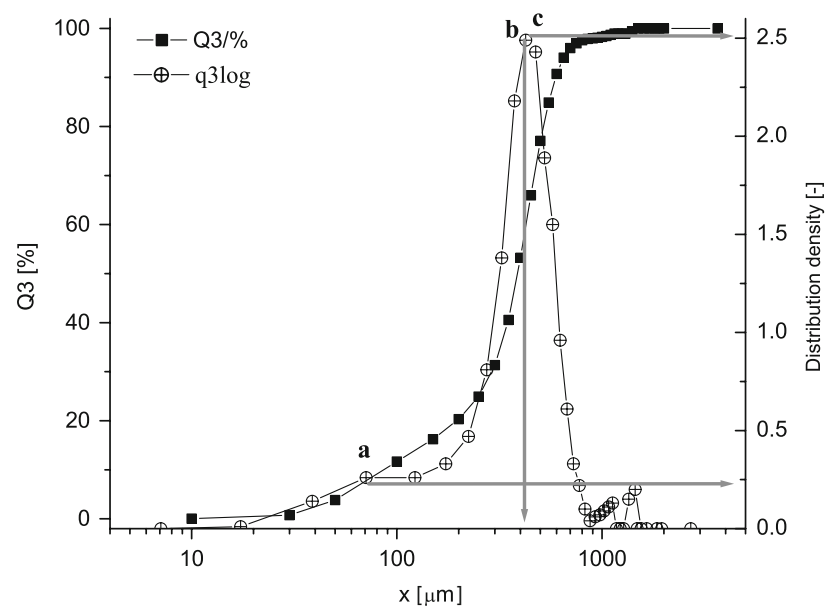

Fig. 1 Particle size distribution and distribution density of LT 1 roasted coffee ground after equilibration time of $24 \mathrm{~h}$ (a distribution density at $70.71 \mu \mathrm{m}, \mathbf{b}$ particle size at absolute maximum, $\mathbf{c}$ distribution density at absolute maximum) for differentiation: distribution density at $70.71 \mu \mathrm{m}$, average particle size at the absolute maximum, and distribution density at the absolute maximum (Table 2). High water content in roasted coffee leads to less brittleness of coffee beans [10], and, therefore, more energy is needed to comminute them. The resulting ground coffee is coarser with increasing water content. The importance of the application of equilibration time before grinding is shown in Fig. 2. While for coffees exhibiting low water content, differences in particle size distributions were rather small with different equilibration time, medium moist roasted coffees required a certain resting time before grinding in order to obtain satisfactory fineness. However, excessive moisture contents ( $>6 \mathrm{~g} /$ $100 \mathrm{~g} \mathrm{wb}$ ) lead to unacceptable grinding results with regard to particle size distribution even after $24 \mathrm{~h}$ of equilibration. It has to be noted at this point that the legal limit for moisture content is usually $5 \mathrm{~g} / 100 \mathrm{~g} \mathrm{wb}$.

Extraction yield and percolation time

Extraction yields depended on roasting time and water content (Fig. 3). The longer roasted coffees exhibited lower extraction yields than the normal time roasted coffees, which confirms results found in earlier studies [11]. Within same roasting times, coffees with higher water content were less efficiently extracted than low moisture coffees. As seen in the preceding paragraph, higher water content lead to larger particles and, therefore, to less surface after grinding, which was probably the main reason for diminished extraction yield.
Table 2 Distribution density at $70.71 \mu \mathrm{m}$, average particle size at the absolute maximum, and distribution density at the absolute maximum for coffees ground after different equilibration times prior to grinding a Batch designation according to Table 1

\begin{tabular}{llllll}
\hline $\begin{array}{l}\text { Equilibration } \\
\text { time before } \\
\text { grinding (h) }\end{array}$ & Batch $^{\mathrm{a}}$ & $\begin{array}{l}\text { Water content } \\
(\mathrm{g} / 100 \mathrm{~g} \text { wb })\end{array}$ & $\begin{array}{l}\text { Distribution } \\
\text { density } \\
\text { at } \times=70.71 \mu \mathrm{m}\end{array}$ & $\begin{array}{l}\text { Average particle } \\
\text { size at absolute } \\
\text { maximum }(\mu \mathrm{m})\end{array}$ & $\begin{array}{l}\text { Distribution } \\
\text { density at } \\
\text { absolute maximum }\end{array}$ \\
\hline 0 & NT 1 & 2.3 & 0.30 & 424.26 & 2.52 \\
0 & NT 2 & 5.1 & 0.28 & 424.26 & 2.17 \\
0 & NT 3 & 8.8 & 0.13 & 1949.36 & 2.94 \\
0 & LT 1 & 2.9 & 0.26 & 424.26 & 2.50 \\
0 & LT 2 & 3.6 & 0.24 & 424.26 & 2.10 \\
0 & LT 3 & 5.9 & 0.18 & 524.40 & 2.06 \\
6 & NT 1 & 2.3 & 0.31 & 424.26 & 2.36 \\
6 & NT 2 & 5.1 & 0.24 & 474.34 & 2.50 \\
6 & NT 3 & 8.8 & 0.17 & 874.64 & 3.42 \\
6 & LT 1 & 2.9 & 0.28 & 424.26 & 2.55 \\
6 & LT 2 & 3.6 & 0.26 & 474.34 & 2.44 \\
6 & LT 3 & 5.9 & 0.21 & 524.40 & 2.49 \\
24 & NT 1 & 2.3 & 0.30 & 424.26 & 2.50 \\
24 & NT 2 & 5.1 & 0.25 & 424.26 & 2.65 \\
24 & NT 3 & 8.8 & 0.18 & 574.46 & 2.58 \\
24 & LT 1 & 2.9 & 0.26 & 424.26 & 2.49 \\
24 & LT 2 & 3.6 & 0.27 & 424.26 & 2.57 \\
24 & LT 3 & 5.9 & 0.25 & 474.34 & 2.54 \\
\hline & & & & &
\end{tabular}




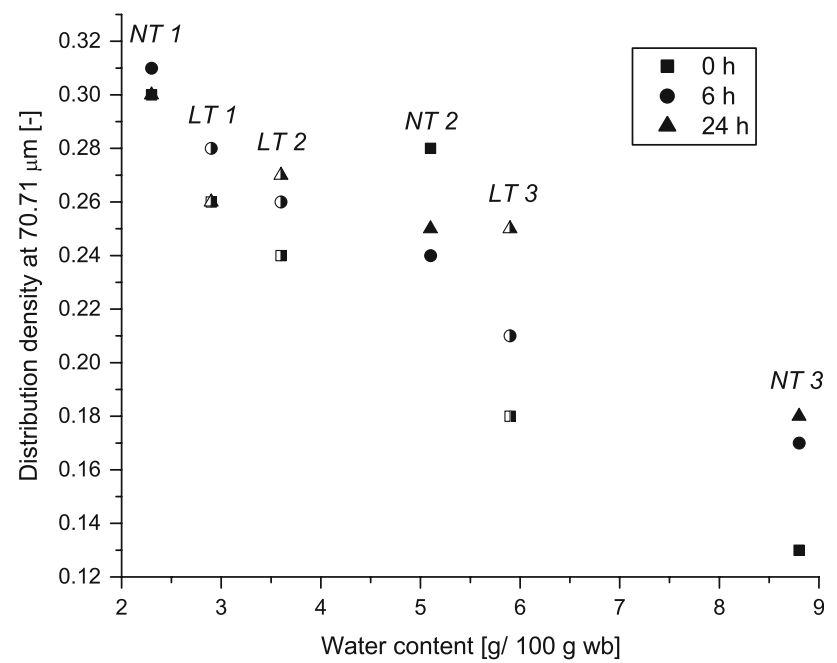

Fig. 2 Influence of water content and equilibration time prior to grinding on distribution density at average particle size of $70.71 \mu \mathrm{m}$. Abbreviations of roasting trials according to Table 1

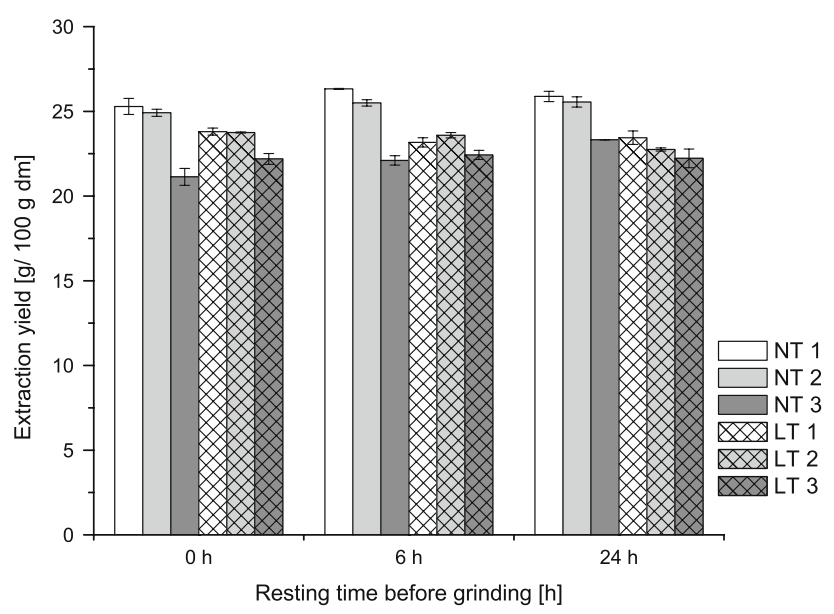

Fig. 3 Extraction yields of roast and ground coffees. Resting times of 0,6 , and $24 \mathrm{~h}$ were applied prior to grinding. Abbreviations of roasting trials according to Table 1

The differences in particle size distribution of ground coffees with different water contents influenced percolation in a similar manner as extraction yield. Grinding of coffees with higher water content resulted in less fine particles, and hence, faster percolation times (Fig. 4). These results are in agreement with those of other researchers [6]. Although particles were very coarse, percolation time of NT 3 ground directly after roasting was high. This is probably an effect of the relatively large ground coffee volume, which lead to excessive filling volume and inefficient percolation in the espresso machine.

Impact of resting time prior to grinding was different for extraction and percolation. Extraction yield seemed not to be affected much by the resting time. Only the extraction yield of NT 3 increased with increasing resting time-but as described above, the low extraction in the case where no

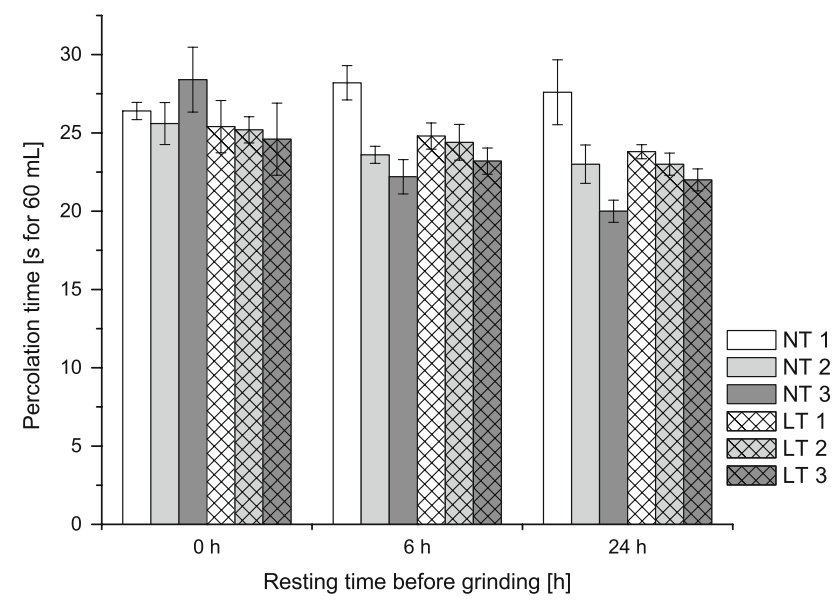

Fig. 4 Percolation times of $60 \mathrm{~mL}$ water through roast and ground coffees packaged in capsules $(6.3 \mathrm{~g})$. Resting times of 0,6 , and $24 \mathrm{~h}$ were applied prior to grinding. Abbreviations of roasting trials according to Table 1

resting time was applied might also be due to technical difficulties. In contrast, percolation times generally decreased with increasing resting times.

Evolution of aroma compounds during storage of roast and ground coffee

Changes of coffee aroma were assessed using the evolution of several typical aroma compounds. The examined substances were aroma impact compounds [12], with the exception of dimethyl sulfide (freshness marker [13]), hexanal (secondary product of lipid oxidation), and pyridine (relatively stable component of coffee volatiles).

\section{Open storage of roast and ground coffee}

Volatile compounds in roast and ground coffee were very rapidly lost by stripping and degradation (Fig. 5; Table 3). Loss of dimethyl sulfide, for example, was more than $80 \%$ within one single day of storage. Alteration of 2-methylbutanal, 3-methylbutanal, 2,3-butanedione, 2,3-pentanedione, 4-vinylguaiacol, and pyridine seemed to be independent of water content. Similar results were already obtained in an earlier study on storage of whole coffee beans [10]. In contrast, decrease of dimethyl sulfide was faster with increasing water content. Concentration of dimethyl trisulfide increased in the first days of storage and then slightly decreased during the following weeks. The coffee with highest water content (NT 3) seemed to behave in a very different manner than the other coffees, since at time zero, concentration was considerably higher than in the other coffees, and a fast decrease was observed (Fig. 5). It is assumed that the accumulation of dimethyl trisulfide starts immediately after roasting, even under protective 

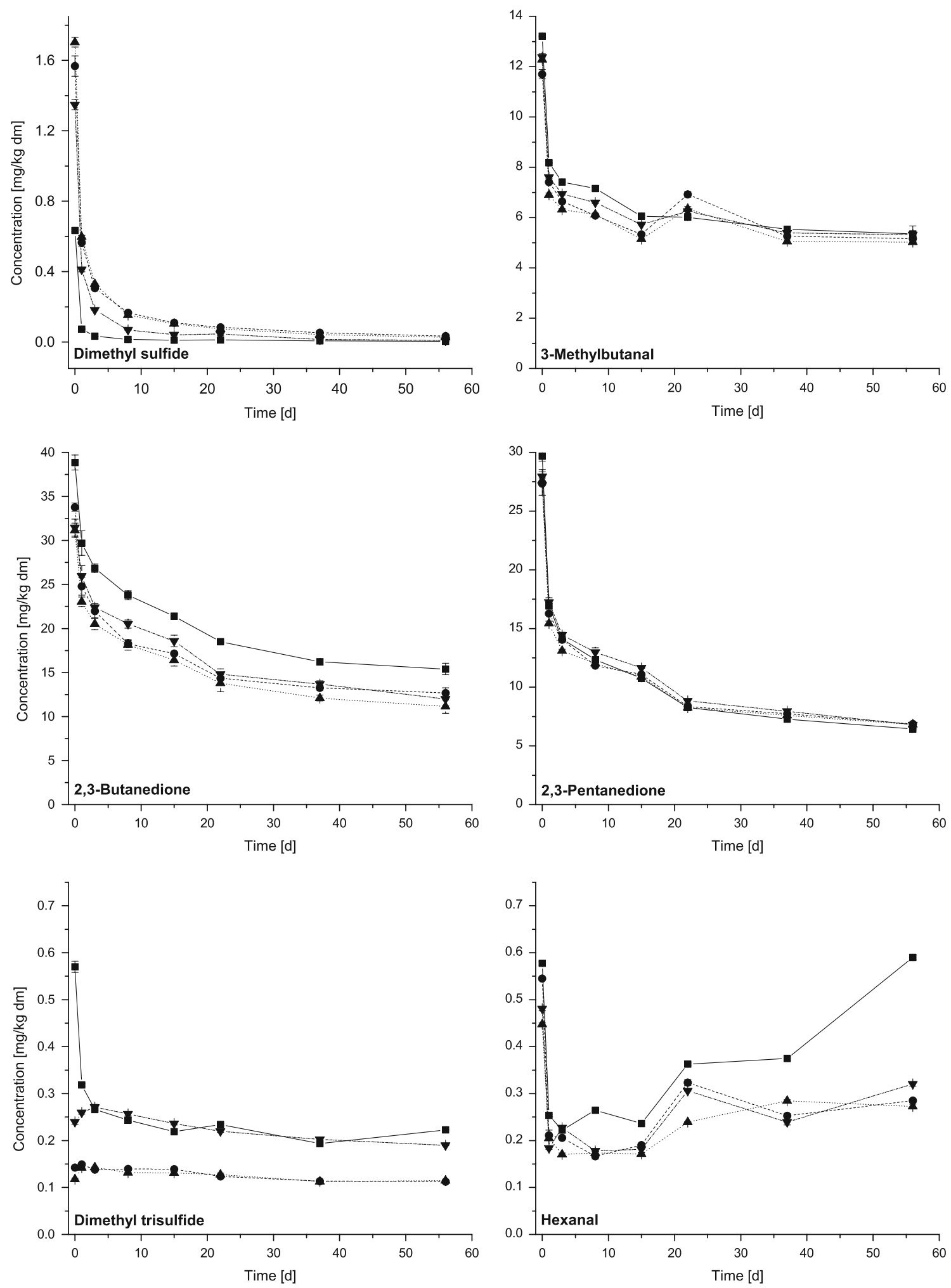

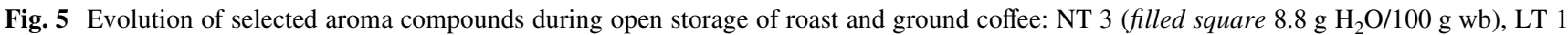
(filled circle $2.9 \mathrm{~g} \mathrm{H}_{2} \mathrm{O} / 100 \mathrm{~g} \mathrm{wb}$ ), LT 2 (filled triangle $3.6 \mathrm{~g} \mathrm{H}_{2} \mathrm{O} / 100 \mathrm{~g} \mathrm{wb}$ ), LT 3 (filled inverted triangle $5.9 \mathrm{~g} \mathrm{H}_{2} \mathrm{O} / 100 \mathrm{~g} \mathrm{wb}$ )

conditions. As mentioned in "Materials and methods", the point of origin of aroma changes was determined using coffee that was ground, packaged under nitrogen, and analysed after $24 \mathrm{~h}$. Therefore, in the case of dimethyl trisulfide, the results of aroma analysis at time zero assumingly do not reflect the real concentration directly after grinding due to 
Table 3 Percent retention of aroma compounds after 56 days of open storage of roast and ground coffee

a Batch designation according to Table 1

${ }^{b}$ Water content is expressed as grams of $\mathrm{H}_{2} \mathrm{O} / 100 \mathrm{~g}$ wb

\begin{tabular}{|c|c|c|c|c|}
\hline \multirow[t]{3}{*}{ Batch $^{a}$} & \multicolumn{4}{|c|}{ Retention (\%) } \\
\hline & LT 4 & LT 5 & LT 6 & NT 3 \\
\hline & $2.9 \mathrm{~g} \mathrm{H}_{2} \mathrm{O}^{\mathrm{b}}$ & $3.6 \mathrm{~g} \mathrm{H}_{2} \mathrm{O}^{\mathrm{b}}$ & $5.9 \mathrm{~g} \mathrm{H}_{2} \mathrm{O}^{\mathrm{b}}$ & $8.8 \mathrm{~g} \mathrm{H}_{2} \mathrm{O}^{\mathrm{b}}$ \\
\hline Dimethyl sulfide & 2.1 & 1.6 & 0.7 & 0.7 \\
\hline Dimethyl trisulfide & 79.2 & 97.4 & 79.2 & 39.1 \\
\hline Hexanal & 52.3 & 60.9 & 66.6 & 102.2 \\
\hline 2-Methylbutanal & 41.7 & 39.7 & 39.7 & 33.9 \\
\hline 3-Methylbutanal & 44.1 & 40.9 & 43.0 & 40.5 \\
\hline 4-Vinylguaiacol & 61.4 & 56.6 & 66.6 & 62.5 \\
\hline Pyridine & 56.5 & 58.6 & 62.5 & 60.6 \\
\hline 2,3-Butanedione & 37.5 & 35.7 & 38.1 & 39.6 \\
\hline 2,3-Pentanedione & 25.1 & 24.7 & 24.3 & 21.7 \\
\hline
\end{tabular}

fast accumulation of this compound. Indeed, in a recent work it was shown that, in whole coffee beans, the increase of dimethyl trisulfide during the first period of storage is directly related to the water content of coffee beans [10]; therefore, an over-estimation of dimethyl trisulfide concentration at $\mathrm{t}=0$ is assumed and increasing water content would lead to more severe over-estimation. Interestingly, a relatively stable concentration of dimethyl trisulfide was attained after about 7 days of storage. This equilibrium concentration was dependent on water content (Fig. 5). As dimethyl trisulfide is an end product of thiol oxidation, these findings indicate faster oxidation of thiols due to increasing water content in roast and ground coffee.

Hexanal concentrations decreased in all coffees during the first few days and increased afterwards. Re-increase of hexanal was fastest in the normal time roasted coffee with highest moisture content (NT 3), while no difference was found between the long time roasted coffees. Hence, fast hexanal increase might be an effect of shorter roasting time leading to larger oil migration due to higher roasting temperature [14], and/or an effect of excessive moisture content of NT 3.

\section{Closed storage of roast and ground coffee}

Evolution of volatile compounds of roast and ground coffee stored in single sealed small containers was similar to changes of volatiles in open stored coffee (Fig. 6; Table 4). Compared to the long time roasted coffees (LT 1, LT 2, LT 3) with water contents of $2.9,3.6$, and $5.9 \mathrm{~g} / 100 \mathrm{~g} \mathrm{wb}$, the normal time roasted coffee with highest moisture content $(8.8 \mathrm{~g} / 100 \mathrm{~g} \mathrm{wb})$ exhibited considerably faster decrease of 3-methylbutanal, 2,3-butanedione, 2,3-pentanedione, and 4-vinylguaiacol (Table 4). Loss of dimethyl sulfide was faster in both high moisture coffees LT 3 and NT 3. Concentration of dimethyl trisulfide increased during the first days of storage to attain a stable amount depending on the water content. The value of the equilibrium concentration of dimethyl trisulfide was 2-3 times higher in closed storage than in open storage. Lower overall losses and a shift of equilibrium between matrix and headspace to the matrix could be reasons for the higher accumulation of dimethyl trisulfide in the closed system.

Loss of aroma compounds was decelerated compared to open storage, but still fast, since capsules were packaged under normal atmosphere. After 56 days of storage, concentrations of 2-methylbutanal, 3-methylbutanal, 4-vinylguaiacol, pyridine, and 2,3-butanedione were about 1.5 times higher compared to open stored coffees. The remaining amounts of dimethyl sulfide and 2,3-pentanedione were even around 5 times and 2 times higher, respectively. The amount of pyridine remained stable throughout storage. Similar results were obtained by other authors [15], who also showed that in single sealed portions of roast and ground coffee, fast decrease in levels of 2-furfurylthiol and dimethyl sulfide took place at an oxygen levels equal or higher than $5 \%$, while at an oxygen level of $2 \%$, these degradation reactions were significantly slowed.

Evolution of hexanal showed that lipid oxidation was slowed in closed packaged coffee. Under these conditions of restricted oxygen supply, the coffee with lowest water content exhibited fastest lipid oxidation, which is in agreement with results on oxidative stability of low-moisture foods by other authors [16].

These figures corroborate the fact that closed packaging slows loss of aroma compounds in ground coffee to a certain degree, but at the same time it is obvious that shelflife cannot be largely extended in closed packages without protective atmosphere. In contrast to open storage, differences in storage behaviour between coffees with low and high water content were visible, due to the slightly better storage conditions in closed package. Therefore, the assumption is made that increased water content leads to shorter product shelf-life due to faster degradation of aroma compounds. A 

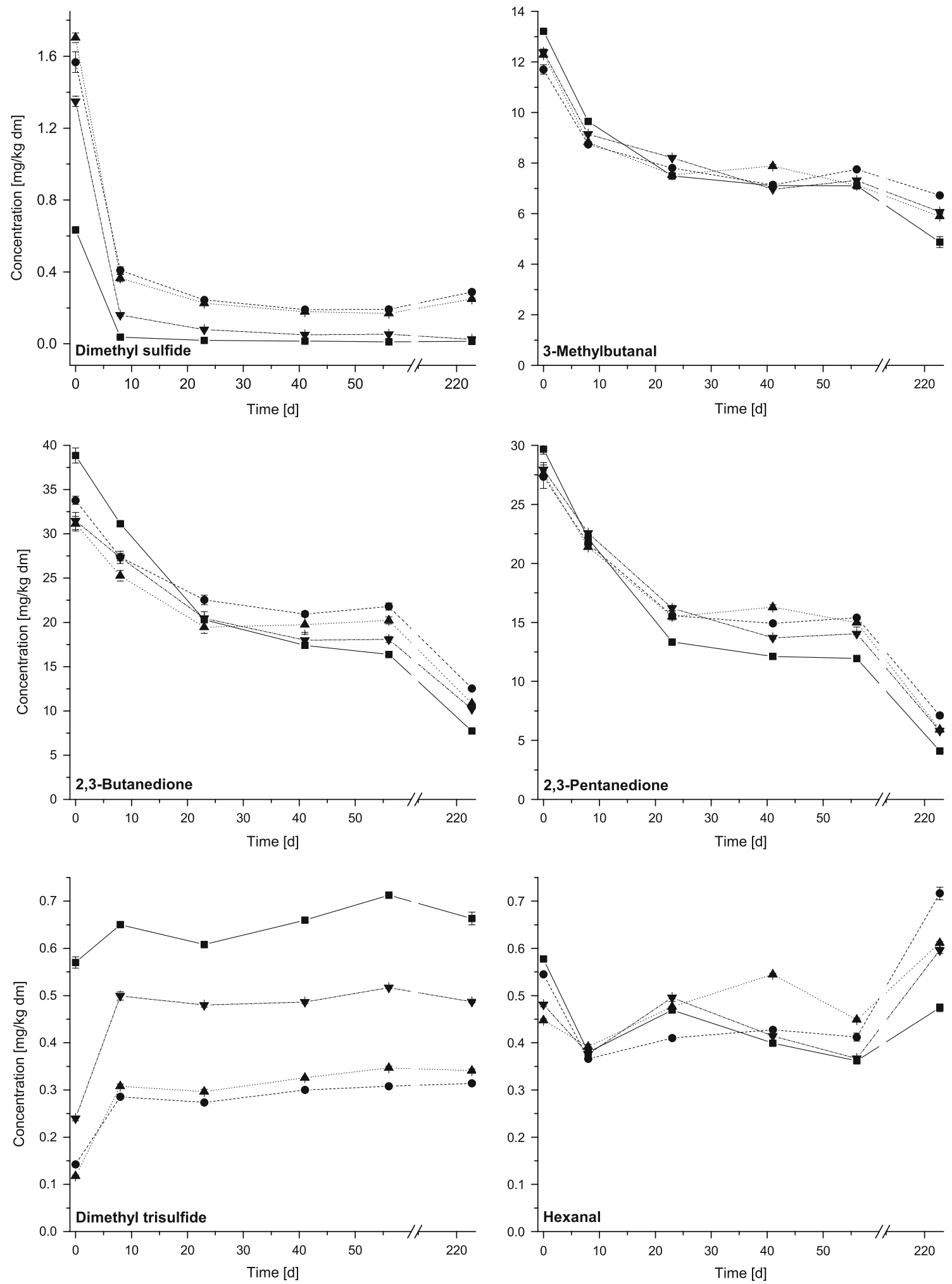

Fig. 6 Evolution of selected aroma compounds during storage of roast and ground coffee in capsules: NT 3 (filled square $8.8 \mathrm{~g} \mathrm{H}_{2} \mathrm{O}$ / $100 \mathrm{~g} \mathrm{wb}$ ), LT 1 (filled circle, $2.9 \mathrm{~g} \mathrm{H}_{2} \mathrm{O} / 100 \mathrm{~g} \mathrm{wb}$ ), LT 2 (filled

triangle $3.6 \mathrm{~g} \mathrm{H}_{2} \mathrm{O} / 100 \mathrm{~g} \mathrm{wb}$ ), LT 3 (filled inverted triangle $5.9 \mathrm{~g} \mathrm{H}_{2} \mathrm{O} / 100 \mathrm{~g} \mathrm{wb}$ ) 
Table 4 Percent retention of aroma compounds after 224 days of storage of roast and ground coffee in capsules

a Batch designation according to Table 1

${ }^{b}$ Water content is expressed as grams of $\mathrm{H}_{2} \mathrm{O} / 100 \mathrm{~g}$ wb

\begin{tabular}{|c|c|c|c|c|}
\hline \multirow[t]{3}{*}{ Batch $^{a}$} & \multicolumn{4}{|c|}{ Retention (\%) } \\
\hline & LT 4 & LT 5 & LT 6 & NT 3 \\
\hline & $2.9 \mathrm{~g} \mathrm{H}_{2} \mathrm{O}^{\mathrm{b}}$ & $3.6 \mathrm{~g} \mathrm{H}_{2} \mathrm{O}^{\mathrm{b}}$ & $5.9 \mathrm{~g} \mathrm{H}_{2} \mathrm{O}^{\mathrm{b}}$ & $8.8 \mathrm{~g} \mathrm{H}_{2} \mathrm{O}^{\mathrm{b}}$ \\
\hline Dimethyl sulfide & 18.4 & 14.6 & 1.9 & 2.1 \\
\hline Dimethyl trisulfide & 220.6 & 289.7 & 203.2 & 116.3 \\
\hline Hexanal & 131.4 & 136.6 & 123.9 & 82.1 \\
\hline 2-Methylbutanal & 70.2 & 57.3 & 62.1 & 57.3 \\
\hline 3-Methylbutanal & 57.4 & 48.0 & 49.0 & 36.9 \\
\hline 4-Vinylguaiacol & 42.4 & 39.6 & 36.7 & 18.6 \\
\hline Pyridine & 109.3 & 106.7 & 114.3 & 109.6 \\
\hline 2,3-Butanedione & 37.1 & 34.8 & 32.4 & 19.9 \\
\hline 2,3-Pentanedione & 26.0 & 21.5 & 20.9 & 13.9 \\
\hline
\end{tabular}

possible explanation for higher rates of degradation reactions is the plasticising effect of increased moisture content, shown by firmness measurements using a shear test in a Kramer cell [10]. Increase of moisture leads to reduction of glass transition temperature in amorphous systems [17], and, subsequently, to higher mobility of reactants [18], including faster oxygen diffusion.

Acknowledgments We gratefully acknowledge the funding of this work by G.W. BARTH Ltd., Freiberg, Germany. We thank Nestlé PTC Orbe, Switzerland, for assistance in aroma analysis, and Delica AG, Birsfelden, Switzerland, for supplying green coffee, offering access to roasting and grinding equipment, particle size analyses, and determination of percolation times.

\section{References}

1. Sievetz M, Desrosier NW (1979) Coffee technology. The AVI Publishing Company, Westport

2. Illy A, Viani R (1995) Espresso coffee: the chemistry of quality. Academic Press, London

3. Petracco M, Marega G (1991) 14th international scientific colloquium on coffee, San Francisco. ASIC, Paris, France, pp 319-330

4. Andueza S, De Pena MP, Cid C (2003) J Agric Food Chem 51:7034-7039
5. Puhlmann R, Habel G (1989) Lebensmittelindustrie 36:161-163

6. Cappuccio R, Suggi-Liverani F (1999) 18th international scientific colloquium on coffee, Helsinki. ASIC, Paris, France, pp $173-178$

7. Fischer C (2004) Kaffee-Änderung physikalisch-chemischer Parameter beim Rösten, Quenchen und Mahlen. Dissertation, TU Braunschweig, 2004

8. Bell LN, Wetzel CR, Grand AN (1996) Food Res Int 29:785-789

9. Spiro M, Selwood RM (1984) J Sci Food Agric 35:915-924

10. Baggenstoss J, Poisson L, Luethi R, Perren R, Escher F (2007) J Agric Food Chem 55:6685-6691

11. Schenker SR (2000) Investigations on the hot air roasting of coffee beans. Dissertation No. 13620, Eidgenoessische Technische Hochschule Zuerich (ETH), 2000

12. Czerny M, Mayer F, Grosch W (1999) J Agric Food Chem 47:695-699

13. Audouin VP (2002) Sensory importance and interactions of character impact compounds in brewed coffee model systems. PhD, University of Minnesota, 2002

14. Schenker S, Handschin S, Frey B, Perren R, Escher F (2000) J Food Sci 65:452-457

15. Poisson L, Koch P, Kerlerl J (2006) 21st International Conference on Coffee Science, Montpellier. ASIC, Paris, France, pp 396-400

16. Labuza TP, Tannenbaum SR, Karel M (1970) Food Technol 24:543

17. Bell LN (1995) Food Res Int 28:591-597

18. Karmas R, Buera MP, Karel M (1992) J Agric Food Chem 40:873-879 